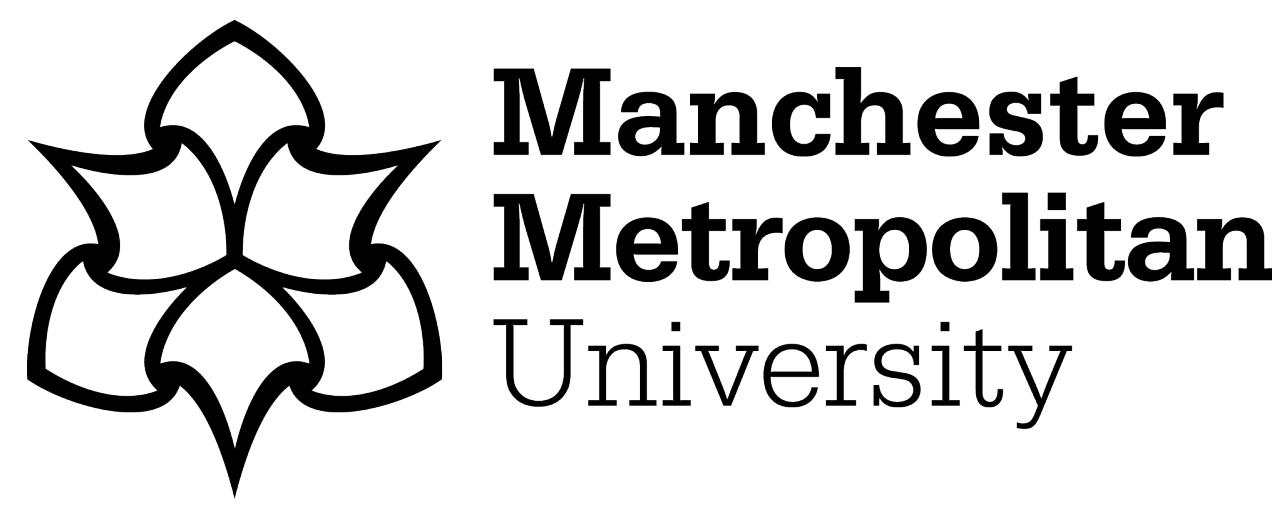

de Freitas, Elizabeth (2016) Number sense and the calculating child: Measure, multiplicity and mathematical monsters. Discourse: Studies in the Cultural Politics of Education, 37 (5). pp. 650-661. ISSN 0159-6306

Downloaded from: https://e-space.mmu.ac.uk/623683/

Version: Accepted Version

Publisher: Informa UK Limited

DOI: https://doi.org/10.1080/01596306.2015.1075703

Please cite the published version 


\title{
Number sense and the calculating child: Measure, multiplicity and mathematical monsters
}

\author{
Elizabeth de Freitas*
}

Manchester Metropolitan University, Education and Social Research Institute, UK

\begin{abstract}
Children and animals of all kinds are said to develop some degree of number sense. The search for 'number neurons' and neural correlates of computational thinking aims to identify biological primitives to explain the emergence of number sense. This work typically looks for the sources of number sense in organisms, but one might extend this search and study the possibility of a calculating matter more generally. Such a speculative project explores the implications of the nonhuman turn within the posthumanities. In this paper I draw primarily on the work of Vicky Kirby and Gilles Deleuze in order to focus on becoming-monster through calculation. I show how calculation, as a machinic and empirical act that both serves and troubles images of mathematical truth, has always played a unique role in the production of mathematical monsters. I then discuss calculating children who participate in abacus clubs and annual abacus competitions, calculating at inhuman rates with imaginary abacuses. I argue that a new materialist philosophy of immanence demands a radically new approach to number sense.
\end{abstract}

Keywords: number; calculation; computation; immanence; Deleuze; Kirby

\section{Published as}

de Freitas, E. (2016). Number sense and calculating children: Multiplicity, measure and Mathematical monsters. Discourse: Studies in the Cultural Politics of Education, 37(5), 650-661.

\section{Introduction}

Children and animals of all kinds are said to develop some degree of number sense (Nieder \& Dehaene, 2009). Tests of basic number sense typically demand counting and calculation of some kind, often using visual and symbolic quantities (Chinn, 2015). Cognitive research on 'number neurons' and neural correlates of 'computational thinking' aims to identify biological primitives that might explain the emergence of number sense (Dehaene, 2011). This work typically looks for the sources of number sense in the conscious actions of organisms, but one might extend this search and study the possibility of a calculating matter more generally. Such an approach might find

\footnotetext{
*Email: defreitas@adelphi.edu
} 
number sense everywhere, immanent within matter. Massumi (2014), for example, mentions research on people performing multistep mathematical operations 'nonconsciously' (p. 43), and claims that this is evidence of how calculation is deeply nonhuman. Kirby (2011) explores swarm behavior and the prospect of a non-human mathesis naturalis that operates in and through material assemblages. Perhaps this work points to the alien qualities of mathematics, to how mathematics is a 'denaturing of man, a transmigration of his essence, a positive becoming-monster' (Badiou, 2006, p. 19).

In this paper I explore the concept of becoming-monster through mathematics. I focus on calculation and its unique role in this process, in part because calculation has always been seen as a machinic and empirical act that both serves and troubles images of mathematical truth. In other words, calculation is typically associated with machinic computation and refers to the hard labor of number crunching, rather than 'higher-order' acts of insight and understanding. Thus one might imagine calculation as the engine of compliant computational ecologies, ubiquitous computing, and the control society (Halpern, 2014). On the other hand, repetitive and recursive calculation is often at the heart of mathematical invention.

This paper looks at the concept of mathematical monsters in order to unpack the relationship between monster and calculation. I first discuss one infamous example of a mathematical monster - named the Koch snowflake - in order to examine the way that conflicting measures of multiplicity are at play in the monstrous. My aim is to highlight the way that calculation brings forth fabulous monsters through recursive automaticity. My hope is that this discussion opens up new ways of thinking about the non-human dimensions of number sense. I then discuss examples of calculating children that seem to trouble our image of the creative child. I consider calculating savants and children who participate in abacus clubs and annual abacus competitions, speed-gesturing with imaginary abacuses as they calculate at seemingly inhuman rates.

It's essential to bear in mind the ethical risks as we explore the monstrous power of calculation in this neo-liberal era of digital labour. Social theory has always explored the dangerous terrain where number and matter commingle, mapping the links between the one and the many, whether it be within the bodies of individuals or the collective movements of groups. Thus the question of how measure relates to matter is at the heart of social theory. Research on education and number sense is a perfect example of how matter and measure are brought together, all too often serving a society of control and prescription. But my aim in this paper is to trouble the all too easy claim that measure is imposed on matter as a control. This paper explores alternative ontologies of measure that might offer social theory a way to think about the immanence of number sense.

Throughout the paper, I explore the relationship between measure, multiplicity and the monstrous.

\section{Monster and measure}

Mathematicians use the term 'monster' to refer to a mathematical entity that seems to break with convention. Mathematical monsters are not quite paradoxical, but somehow unruly and uncooperative, and yet also a source of potential invention. ${ }^{1}$ Examples of monsters are everywhere in mathematics, as though the discipline itself were a breeding 
ground for them. Indeed, the philosopher of mathematics Imre Lakatos (1976) argued that mathematics is a dialectical process of creating opportunities for monsters to be born and then redesigning the rules in order to banish them.

One infamous mathematical monster is the Koch snowflake - a curve that is everywhere continuous but nowhere differentiable. Such a curve would be smooth in one sense - in being continuous - but its curvature so jagged that there would be no way to track its abrupt changes. This snowflake is recursively ever-expanding as each perimeter segment is repeatedly partitioned indefinitely (see figure \#1 for the first 4 iterations). Eventually, as this process continues, the neighborhood around every point on the perimeter becomes so jagged and prickly that one cannot navigate easily.
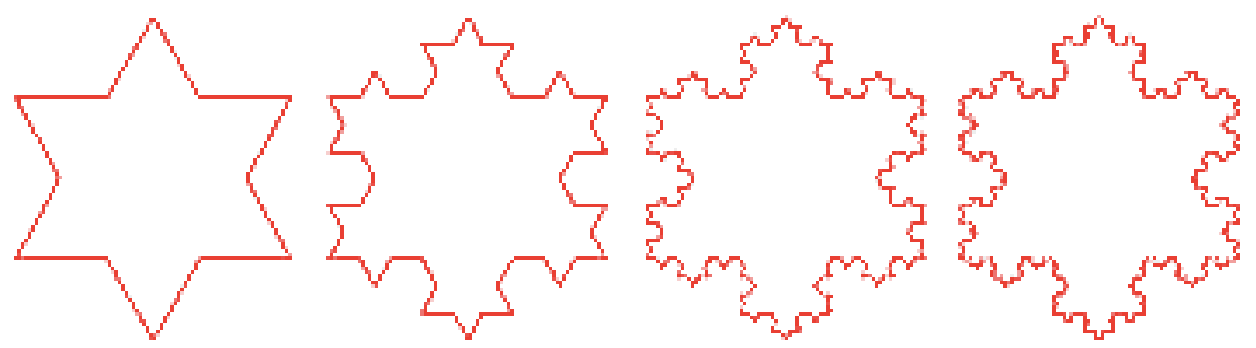

Figure 1: Koch snowflake

This machinic fractal snowflake is generative of facts that run counter to expectation, including the fact that the perimeter ultimately becomes infinite, but somehow - contrary to expectation - the area within the snowflake remains finite. In other words, as the fractal border proliferates indefinitely creating an infinite border, the space contained within the border remains finite. ${ }^{2}$ This co-occurrence of the finite and the infinite is often where monsters are born in mathematics, as though mathematics was ultimately a means for exploring and mobilizing the fundamental metaphysical problem of how the finite relates to the infinite.

As a poster-child for mathematical monsters, the Koch snowflake exhibits a cold calculating tendency while at the same time refusing to cater to our expectations about measure. The proliferating edge of the perimeter pursues an iterative alteration, a repetition of difference, an estrangement of the sensory-motor hand that might reach out to trace its movement. This insistent iterative process of becoming unmanageable through repetition transforms thought itself as one pursues the fractal fold.

In the case of the Koch snowflake, as in the case of many mathematical monsters, the monstrous emerges as resistance to measure. The derivative - which is the measure of how fast a curve is changing - cannot be calculated. One way of interpreting this claim is to suggest that there is a dialectical relationship between measure and monster, as Lakatos claimed, whereby resolution is achieved through increased constraints and ultimate axiomatization. In such resolutions, the measure negates or destroys the monster. Another way of interpreting this is to think of measure and monster as imbricated, so that 'resolution' is studied in terms of reconfiguring their assemblage rather than the negating of one by the other. Rethinking relations such as this without always casting them 
dialectically allows us to imagine complex relational ontologies, where becoming monstrous is also becoming measure.

Pursuing this line of thought allows us to consider calculating and computation less as the enemy of creative children, and more as evidence of how humans are always already non-human. As Manning (2015) says of art, there is always 'a rigorous process that consists in pushing technique to its limit, revealing its technicity' (p. 48). This technicity becomes more than confining habit when it is attuned to the force of its own potential, when it evolves into a technicity that unleashes 'a becoming that could not have been mapped in advance' (p. 60).

But rather than exclude the quantitative from the world of becoming, as Manning does, I want to suggest that number itself must be allowed to partake in this transindividual force. Mathematical monsters like the Koch snowflake are machinic in some fundamental way, exploring the extreme limit cases of familiar measures. The fractal folding of the perimeter stretches our sense of measure into new and uncomfortable terrain. The unending partitioning of edges evokes a certain madness or compulsive behavior. The fractal compels one to perform this partition upon the previous partition, again and again. Only through such dogged repetition do we arrive at the multiplicity within the multiplicity - only then does the fabulous monster emerge.

Measures in the social sciences are typically stochastic and based on the counting of discrete data points. Digital technologies lend themselves to this approach because they operate with binary logic. At its most basic, counting involves isolating entities so that each can be counted. At its most advanced, counting becomes computation, and at great speeds computation becomes the art of 'perceiving' large sets of discrete data points as one continuous fabric. It is this odd but powerful leap from the discrete atomism of individuals to the flowing continuity of a surface that allows us to merge the countable with the uncountable. But this merging always haunts us, as though disturbed by the sudden loss of individuated points as they fall into the flow of the continuous.

The media theorist Sha Xin Wei (2013) suggests that computation is actually a process of crenulation and foliation, and thus part of the ontogenetic folding of matter rather than something imposed on it from without. One might, however, interpret this as the claim that number is a priori pre-given in matter, a reductive reading that sees only binary logic and decision trees operating at all scales. But that interpretation would treat number as exhausted by its binary actualization. In other words, number would be treated as a finished concept, unable to partake in becoming imperceptible. Following Deleuze, Wei (2013) grants matter a virtual dimension, an inherent potentiality, and allows number and measure to partake in that potentiality. He emphasizes how media are alive with dueling 'parameters' that can be modulated to create odd monsters, like the snowflake, where complexity in form increases through the iterative folding of an environment that is inherently mathematical. He suggests that the monsters of measure theory 'hint at an infinitely richer mathematical ontology ever more prolific than the present imaginary' ( $p$. 140). He encourages us to consider how the recursive process that generates the snowflake is a folding process, and each iteration or count is never fully disconnected from its past and future iterations. Granted, there is an algebraic rule that governs the recursive process, but the rule does not actually foreclose on the potentiality of the fractal. For Wei, the monstrous is precisely when the rule or the form repeats so often it begins to tremble and quake. 


\section{Calculating matter}

Deleuze (1993) draws attention to a Baroque mathematics that infinitely folds the material world. This kind of mathematics comes to Deleuze via Leibniz and his notion of the infinitesimal, and allows him to pursue a monist ontology of infinite pluralism. Monism disallows double standard ontologies, and affirms the pure difference and unbounded proliferation that characterize Deleuze's work. This point is crucial for how it allows us to think about multiplicity in new ways. Monism is indeed what affords Deleuze the theoretical space for a philosophy of immanence that affirms infinite pluralism. Monism is not reductive of difference, because the all-inclusive matter of monism is as deeply virtual as it is actual. Moreover, this infinitely folding monism dissolves form, as the cut-out discrete individual, and thereby offers up new ways of thinking politically about the collective. As Negri (2013) states of this ontology, this is not -

... a materialism of the inert object, any more than it is a materialism arising out of necessary causal sequences. On the contrary, it is a materialism of active differences and subjective dispositifs, that is to say, an assertion of matter as productive force, through the activity of those modalities that constitute substance. (p. 24)

These modalities are nothing more than the modulations of matter - the crenulations, foliations, invaginations - that are continuously actualizing the virtual. For Negri (2013), this new materialism is what offers us the image of a political multitude that is beyond the moral judgment of good and bad:

I would simply like to stress the way in which materialism, when placed under the logical and ontological lens of Spinozism, is able at last to abandon its traditional dialectical status, and how it can, on the contrary, endow itself with a project both constitutive and subjective. (p. 29)

This kind of optimism, however, must grapple with the question posed in this paper: how are measure and number sense incorporated into a philosophy of immanence? Kirby (2011) argues that the mathematics that emerges from this 'animate matter' is not given in advance nor made only for humans to deploy. She challenges one to imagine a mathematics that is not for human consumption alone. Number, especially, is all too often extracted from the vagaries of animate matter, and conceived as the ultimate humanderived tool. Derrida, for instance, will suggest that the success of mathematics in describing the material world will always be interpreted as either a mark of man's achievement or disturbing evidence that mathematics is somehow non-human:

... we can consider algebra from two points of view ... [O]ne thinks of algebra as a field of ideal objects, produced by the activity of what we call a subject, or man, or history, and thus, we recover the possibility of algebra in the field of classical thought; or else we consider it as a disquieting mirror of a world which is algebraic through and through. (Derrida, 1970, cited in Kirby, 2011, p. 19) 
But Kirby suggests that Derrida continues to dislocate mathematics from matter - naming it as 'mirror' - and that he fails to pursue the radical immanence that characterizes the work of Deleuze.

Deleuze's monism reclaims mathematics from its 'mirror' status - as though it were measuring matter from the outside - and incites us to study mathematics as matter. We must ask, what happens to algorithm and number sense within a monist philosophy of radical immanence? According to Kirby (2011), the desire that mathematics be an instrument invented by humans to access a world from which we have been severed reflects a particular phenomenological perspective. At the centre of phenomenology is the human organism for whom the world unfolds. If instead the Koch snowflake captures the way in which mathematics is an 'in-finite differentiation whose fundamental dimensions are still being drawn' (p. 34) then we might be faced with a future mathematics that may not be recognizable to us. As odd as such a suggestion sounds, she asks us to consider how the earth might be investigating itself mathematically:

If we could entertain the possibility that our questions involve these expanded dimensions, then Joyce's equivocity, intuition, and inexactitude might be read as a virtual filigree of fractal arabesques that unfold within objectivation/perception/scientific language. (Kirby, 2011, p. 34)

Measure would then not only be the anthropocentric habit inscribed in Protagoras' aphorism 'man is the measure of all things' nor reflect a unique human capacity. Instead, measure would be a tendency or potentiality of matter. Geometry, for instance, would be a more material mingling of geo and metric. For Kirby, too much of socio-cultural theory forecloses this possibility by defining geometry against geology, language against matter, mathematics as a representation that codes matter from without. Instead she urges us to consider a posthuman mathesis with its own potentiality.

There are grave dangers in removing the human from mathematics, as this opens up the opportunity for ascribing mystifying power to number. Removing or bracketing the human side of mathematics is often associated with a kind of Platonism that tends to favour the notion of inherent mathematical ability on behalf of those who are sufficiently gifted to access the ideal inhuman truths of mathematics. And so it is crucial to critique any project that claims mathematics to be 'a measured discipline practiced by Nature itself, a mathesis naturalis' (Kirby, 2011, p. 56) for many reasons, not least of which the kinds of pedagogies that might be associated with such a claim. And yet bracketing the human does not necessarily lead to Platonic idealism or reductive behaviorism. My aim here is to explore how bracketing the human within a philosophy of radical immanence leads to something quite different. This is not to suggest that there are no dangers along this path. It's all too easy to imagine dystopic scenarios where we pay tribute to a calculating universe with built-in agenda 'where the bourgeois ego is drowned in the icy waters of inhuman labor' (Noys, 2013, p. 93). And doubtless this remains a real danger, as education policy invests in global digital assessment tools and the datafication of learning. While at the micro-level, researchers search for the calculating grey matter that houses number sense in the brains of young children.

\section{Calculating children}


In watching the Koch snowflake expand in an algorithmically controlled manner, one can begin to grasp the power of obsessive calculation, imagining the hand that repeatedly calculates the next iteration. Is it through immersing oneself in calculation that one begins this engagement with becoming-monster? Is calculation the machinic process that will facilitate a trance-like alien quality in our intelligence? Calculating savants have always inspired fascination, and have often been treated cruelly as circus freaks and idiot savants'. Calendar savants - who can calculate the day of the week when given any past or future date - are frequently identified as being on the autistic spectrum. Many of these calculating savants also have flawless recall. Daniel Tammet, a UK savant, exhibited extraordinary calculating skills as a child, and was able to compute 'in the blink of an eye' large and difficult calculations. When asked to recite the first 20,000 digits of the transcendental number $\pi$, he closed his eyes and quietly announced each one correctly during an approximately 5 hour videotaped session. Researchers are interested to know to what extent these calculating savants deploy algorithms that are different from those used by neuro-typicals. Tammet (2012) claims that every number has a shape and colour, and that his calculating simply involves immersing his thoughts into their vibrant and animate environment.

Developing 'number sense' is one of the main objectives of early elementary education, and a key focus of curriculum policy and research. Various definitions of number sense stress different qualities - 'an intuitive understanding', 'a well organized conceptual framework' or 'fluidity and flexibility with number' - while pointing to particular skills, like counting, estimation, calculation, and choosing measurement units (Gersten \& Chard, 1999). Recent research on 'dyscalculia' purports to identify a cognitive disorder that has basis in the physiology of brains (Simms et al., 2014). Much of this research seeks the 'number neurons' in a region of the brain - the intraparietal sulcus - where neurons activate when people perform calculations. Although such research tends to be located within a cognitive psychology paradigm, it also seems relevant to the questions that Kirby raises - questions about the relationship between human calculation and the material world.

Arithmetic skills are usually developed using various material or visual devices, like blocks and cuisenaire rods. One of the most historically significant counting devices is the abacus, a rectangular-shaped counting frame with beads spread across rows. Ancient abacuses were used in Sumerian and Babylonian civilizations for adding, subtracting and multiplying quantities. The beads slide up and down the rows as a way of performing particular operations (see figure 2).

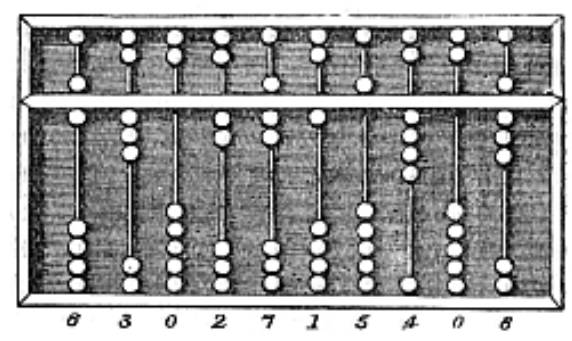

Figure 2: Chinese abacus 
Use of the abacus spread across Africa, Europe and Asia, as an important calculating device. Learning arithmetic on the abacus remains a popular approach, particularly in Asian countries. Annual competitions bring thousands of children together to compete on the abacus, where they complete as many as 125 complicated calculations in under 12 minutes.

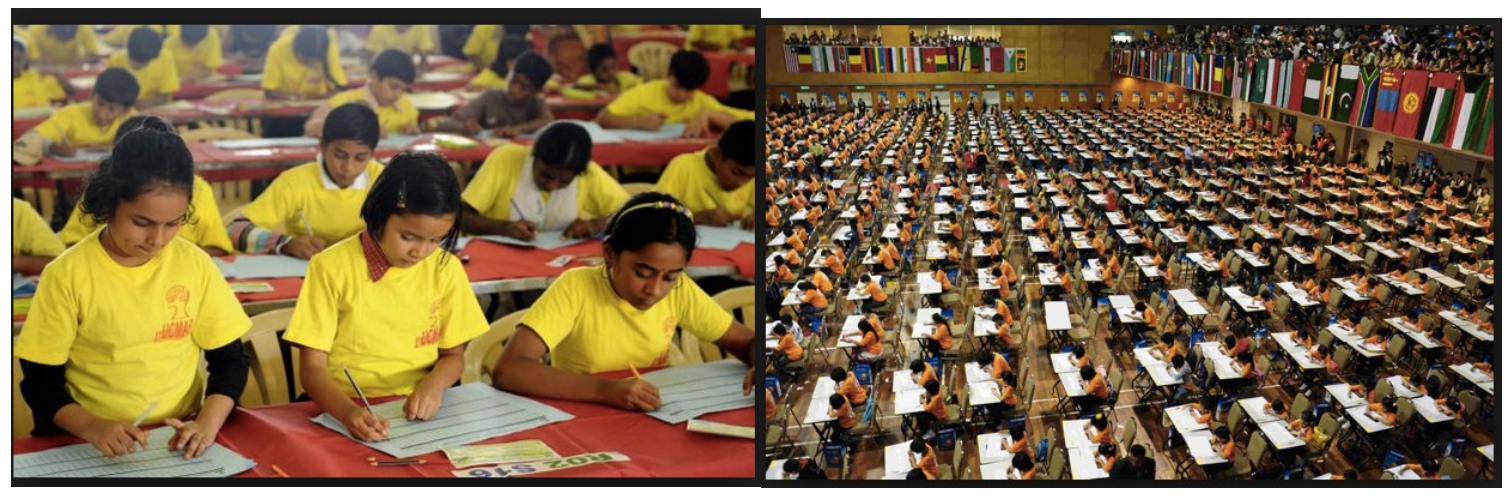

Figures 3 and 4: Calculating children at abacus competitions (source: http://sipacademyindia.com/index.asp)

Participating children use the abacus (or gesture as though they were using the abacus) to complete calculations at record speeds. These competitions celebrate human calculating skills and the power of the abacus to support manual calculation and mental arithmetic. Although electronic calculators require some digital dexterity, the abacus triggers the hand to think in a more expansive way. The child's body becomes the site of the calculation - there is no reflection or pause or memory recall while the mind tallies the count. Competitions (see figures 3 and 4) host thousands of children sitting in one room, each at a desk, in a trance-like calculating calm. Throughout the room, hand gestures repeat and repeat, proliferating across the room, a wave of collective computing. And yet this image of collective human calculation always seems to evoke consternation, as though it were the most inhuman image imaginable. We see a swarm of calculating children, a mass unconscious calculation, a ritual performance of bodily competency. We see the inhuman dimension of calculation, the usurping of the organism, the counting frenzy of the transindividual. In these abacus events we are faced with the impersonal autonomy of decision more generally. We follow the flow of calculation across the transindividual. This image turns away from the phenomenological body of lived experience, towards a cybernetic fantasy of perfect transmission, an example of 'the small cybernetic honeybee engaged in thoughtless, but communicative, actions' (Halpern, 2014, p. 75).

If computation is a kind of difference-making, a digitization that splits, and splits again, the one into the many, or the continuous into the discrete, then we might, like Deleuze, celebrate this difference and proliferation as the monstrous. In other words, it would be the multiplicity of these calculating children that makes them monstrous, a multiplicity that is all the more monstrous because it is a swarm-like trance performance. 
As Deleuze (1994) suggests 'thought "makes" difference, but difference is monstrous' (p. 37). But perhaps, as Galloway (2014) claims, the more monstrous is the world that brings forth a unified digitality, a global digital labor, a world - evoked by this image populated by millions of computers replicating computations at speeds beyond human comprehension. For Deleuze (1992), the control society is achieved by way of 'the new monster' of information society (p. 178). Just as the fold was used by Deleuze to describe the Baroque subject, the 'superfold' or overfold is used to describe the current 'computerized control society' (Galloway, 2014, p. 108). The dividual (rather than the individual) and the superfold are the key tropes of this new era, which is still a folding monist topology, but stretched and twisted into entirely new relationships. The difference between the fold and the superfold is that the latter incorporates the digital. Leibniz' fold is 'the smallest element of the labyrinth' and more fundamental than the point (Deleuze, 1994, p. 6). But the 'superfold' is a combinatorial iteration achieved in the kinds of genetic repetition we see in the double helix, where chance and algorithm commingle. The Baroque subject was pleated into matter, but the post-phenomenological dividual is a recombinant subject, assembling always in relation to the bioinformatic ecosystem. Like the Koch snowflake, this subject is produced through a fractal fold, an iterative jagged fold, which changes so radically at imperceptible scales that competing measures fail to agree. The Koch snowflake captures the fractal shape-shifting of the calculated and calculating dividual of contemporary digital culture.

Thus the control society is not simply imposed on us from without, since computation is within us. We are computational everywhere, from RNA recombination to markets to digesting stomachs to degrees of affect. Deleuze (1989) reminds us that there are at minimum two kinds of automata - the first is the 'great spiritual automaton' which pursues the highest exercise of thought, while the second is the 'psychological automaton' who is 'dispossessed of his own thought' (p. 263). In the first case, automata is lived as immanence. In the second case, it serves the control society and its reliance on a phenomenological (sensory-motor) image of the body. In the first case, we follow a will to art that breaks with a phenomenology of the human body as the administrator of all its participation. This encounter serves a non-human will to art, 'aspiring to deploy itself through involuntary movements', but always risking new methods that may destroy that same will (Deleuze, 1989, p. 266). Such artful automatism recalls Surrealist automatic writing in which the hand becomes a conduit for non-human forces. But rather than see automatism as a conduit or form of communication between the human and the nonhuman, consider instead automatism as pure immanence, as entirely non-representational and non-communicative. What if automatism occurred without representation? How does the control society tap an automatism that is pure immanence? Can we explore a number 'sense' that belongs to matter in this way? A computation that escapes the logic of resemblance, correspondence, exchange, remainder? These questions are precisely those that haunt a philosophy of immanence.

Many scholars have turned to an emphasis on the body as a way to explore immanence, centering the gesture, the stammer, and the diagram as the non-transcendent sites of mathematical thinking (Nemirovsky et al., 2012; Roth, 2010). By emphasizing the empirical, material, situated, historical work of mathematics, the mathematical ideal is made corporeal (de Freitas \& Ferrara, 2014). In this work, the body is not demoted as vehicle of the mental or the ideal, but instead taken to be the generative force of 
mathematical concepts. De Freitas \& Sinclair (2014) push the body beyond its usual skin contour, so that they might address the questions that Kirby raises - When does a body become a body? And why is the mathematics always assumed to be on the outside of that body? As Kirby (2011) asks: 'What arithmetic allows the body's internal differentiations to make sense, whereby what appears as "one" modality can translate to, or anticipate its difference from, another, and finesse discrepancies?' (p. 62). She is seeking the arithmetic and number sense of the body itself. If we push the idea of embodied cognition beyond the phenomenological imaginary, we come to thinking matter. Matter as thought, thought as matter. This is a call to consider how thought operates beneath or alongside our individuated human bodies, how thought might be a force that is somewhat indifferent to these human bodies. Without problematizing the body in this way, the phenomenological project pays heed to a humanist vision of mathematics as that which is always outside of matter. Kirby is pushing us to consider carnality as 'calculating and thinking material through and through' so much so that the very nature of corporeality is 'to mathematize, represent, or intelligently take measure of itself' (p. 63). In other words, we are asked to imagine the non-human dimension of measure. Might it be the case that computation, calculation, and the digital more generally, are the most adequate ways of communing with matter? Such a question seems too dangerous to pose in the midst of calculated publics and governing algorithms and smart environments that track our every move. And yet surely such ubiquitous computing points to the urgent need to directly confront this question.

De Freitas and Sinclair (2014) pursue this agenda, suggesting an 'inclusive materialism' that decentres the human, exploring the non-human forces that participate mathematically in the world. If matter itself explores the mutating but structured fractals of the Koch snowflake, not as given pre-forms but as ontogenetic forces, then there is some sort of mathesis naturalis that entails an 'evolving and implicate calculation' (Kirby, 2011, p. 66). And yet any proposal of a mathesis naturalis becomes increasingly dangerous as we turn to children and schools and other oh so human contexts: 'How should we understand epistemology in such an instance where calculation is an ontologizing process of mutation?' (Kirby, 2011, p. 41). How should we develop curriculum and instruction if calculation is an activity of all matter? How do we cultivate children's number sense as that which is folded into the material universe? There are good reasons for exploring the ethical dimensions of these practical questions, not least of which being global trends in educational research that emphasize big data and neuroscience.

Recent research into 'dyscalculia' as a neurological disorder of young children is typically based in ideas from developmental psychology. The dyscalculia label ascribes learning difficulties to individuals, rather than to any particular socio-politicaltechnological complex. Indeed, the notion of dyscalculia is already used to 'explain' the low performances of certain learners who have been identified as experiencing difficulty in school mathematics. Many scholars question whether dyscalculia describes a specific cognitive deficit, such as Gifford (2006), who points out that no consensus has been reached about its defining characteristics, aside from poor recall of number facts. But the point here is that dyscalculia is meant to describe a malfunctioning of a calculating (grey) matter that, in theory, operates and calculates alongside the process of becoming human. In other words, if we want to ensure that these new global trends in education research 
are used in politically and ethically inclusive ways, whereby neurodiversity is celebrated rather than pathologized, then we need to explore and perhaps reclaim the dangerous idea that there may be some truth to a mathesis naturalis.

\section{Conclusion}

Colebrook (2014) will admonish materialist 'reaction formations' that ascribe an all too human vitality to matter, while she pursues, at the same time, the implications of a posthuman condition. She asks 'Should we not be considering ourselves and conscious life not as emergent properties, but as a monstrosity that we do not feel, live or determine, but rather witness partially, and ex post facto?' (p. 14). Rather than imagine a world revealed to a solicitous subject, as phenomenology does, and a corresponding concern for the degrees of alienation from that given world, Colebrook asks that we imagine a more radical alienation. The problem with phenomenology is that it positions the human perceiver as the arbiter or judge - be that a mental faculty or a neural capacity - which is then locked into a hermeneutics of suspicion regarding possible illusions whereby the 'real' is only a construct or mirage. Projects that emanate from phenomenology always entail this position of reflection (and dejection) and thus lack a sense of urgency and immanence. As Laruelle (2010) states, 'To meditate on the essence of Being, on the forgetting of Being, is a task that has lost its sense of urgency' (p. 21). Such an approach is premised on exchange insofar as illusions and constructs are substituted for the real.

I am interested in a different kind of materialism that pursues immanence (rather than exchange) without the phenomenological centering of the human. This might be deemed a sort of non-human realism, if it weren't for the fact that realism is always about the contours of human belief. For Deleuze and Guattari (1987), the work of Leibniz, Spinoza and Bergson offers a glimpse of what this materialism might look like. These thinkers offer a path into a non-human political ontology of immanence, of univocity and plurality, of the one and the many, where monism=pluralism. But the crucial thing, while exploring a philosophy of immanence, is to not revert to oppressive regimes of truth that exalt in the finitude of measure. When the Cybernetic theorist and founder of "neural nets' Warren McCulloch presented his 1960 lecture 'What is a number, that a man may know it, and a man, that he may know a number?' the desire for control and prediction fueled his speculation. McColloch, inspired by Russell and Whitehead's Principia Mathematica and the search for the logical foundations of mathematics, sought the synthetic a priori material configurations of logic in the brain. He treated the neuron as the material equivalent of a logic gate, and saw his work contributing to a contemporary Kantian project of identifying the a priori physio-logical conditions of judgment (Halpern, 2014). In this paper, I've explored the tensions raised by such a project, as we turn to questions of the immanence of number sense. I've tried to avoid the 'reaction formations' about which Colebrook warns, to resist teleological fantasies that reinstate the human as that for whom the world is given. Following Kirby (2011), I've suggested that a crucial aspect of this project must be rethinking mathematics and measure as dimensions of an unruly world. 


\section{Notes}

${ }^{1}$ For various examples in the mathematical bestiary, see Dr Vogel's gallery of calculus pathologies at http://www.math.tamu.edu/ tvogel/gallery/gallery.html

2 This dilemma can be explored with students using geometric series and simple measurement formulae for area and perimeter of a triangle. With each iteration, smaller triangles are added to the previous stage, generating formulae for perimeter $(\mathrm{P})$ and Area $(\mathrm{A})$ after $\mathrm{n}$ iterations:

$P_{n}=3 s\left(\frac{4}{3}\right)^{n}$ and $A_{n}=A_{0}\left(1+\frac{1}{3} \sum_{k=0}^{n-1}\left(\frac{4}{9}\right)^{k}\right)$

As $n$ approaches infinity, the perimeter expands without limit, but the area converges.

\section{References}

Badiou, A. (2006). Mathematics and philosophy. In S. Duffy (Ed.) Virtual mathematics: The logic of difference (pp. 12-30). Manchester, UK: Clinamen Press.

Chinn, S. (Ed.). (2015). The Routledge International handbook of dyscalculia and mathematical learning difficulties. New York: Routledge.

Colebrook, C. (2014). Sex after life: Essays on extinction, volume 2. Ann Arbor, Michigan: Open Humanities Press.

De Freitas, E., \& Ferrara, F. (2014). Movement, memory, and mathematics: Henri Bergson and the ontology of learning. Studies in Philosophy of Education, 33(6), 1-21.

De Freitas, E., \& Sinclair, N. (2014). Mathematics and the body: Material entanglements in the classroom. London: Cambridge University Press.

Dehaene, S. (2011). The number sense: How the mind creates mathematics. Revised and expanded edition. New York, NY: Oxford University Press.

Deleuze, G. (1989). Cinema 2: The time image. (Trans. Hugh Tomlinson \& Robert Galeta). Minneapolis, MN: The Athlone Press.

Deleuze, G. (1992). Postscript on the societies of control. October, 59(Winter) 1992, 3-7.

Deleuze, Gilles (1993), The Fold: Leibniz and the Baroque, trans. Tom Conley, Minneapolis: University of Minnesota Press.

Deleuze, G. (1994). Difference and repetition. (Trans. Paul Patton). New York, NY: Columbia University Press.

Deleuze, G., \& Guattari, F. (1987). Capitalism and schizophrenia: A thousand plateaus. (Trans. Brian Massumi). Minneapolis: University of Minnesota Press.

Galloway, A. (2014). Laruelle: Against the digital. Minneapolis: University of Minnesota Press.

Gersten, G., \& Chard, D.J. (1999). Number sense: Rethinking arithmetic instruction for students with mathematical disabilities. The Journal of Special Education, 33 (1), 18-28.

Gifford, S. (2006). Discalculia: Myths and models. Research in Mathematics Education, 8 (1), 35-51.

Halpern, O. (2014). Beautiful data: A history of reason and vision since 1945. Durham, NC: Duke University Press.

Kirby, V. (2011). Quantum anthropologies: Life at large. Durham, NC: Duke University Press.

Lakatos, I. (1976). Proofs and Refutations. Cambridge: Cambridge University Press. 
Laruelle, F. (2010). The truth according to Hermes: Theorems on secret and communication (Trans. A. Galloway). Parrhesia, Issue 9, 18-22.

Manning, E. (2015). Artfulness. In R. Grussin (Ed.), The nonhuman turn (pp. 45-80). Minneapolis, MN: University of Minnesota Press.

Massumi, B. (2014). What animals teach us about politics. Durham, NC: Duke University Press.

McCulloch, W. (1960). What is a number, that a man may know it, and a man, that he may know a number? Alfred Korzybski Memorial Lecture, 1960, first published in: General Semantics Bulletin, 26/27, 1960, 7-18.

Negri, A. (2013). Spinoza for our times: Politics and postmodernity (trans. William McQuaig). New York City, NY: Columbia University Pres.

Nemirovsky, R., Rasmussen, C., Sweeney, G., \& Wawro, M. (2012). When the classroom floor becomes the complex plane: Addition and multiplication as ways of bodily navigation. Journal of the Learning Sciences, 21(2), 287-323.

Nieder, A., \& Dehaene, S. (2009). Representation of number in the brain. Annual review of neuroscience, $32,185-208$.

Noys, B. (2013). Malign velocities: Accelerationism and capitalism. Washington, U.S.: Zero Books.

Roth, W.-M. (2010). Incarnation: Radicalizing the embodiment of mathematics. For the Learning of Mathematics, 30(2), 8-17.

Simms, V., Gilmore, C., Cragg, L., Clayton, S., Marlow, N., \& Johnson, S. (2015). Nature and origins of mathematics difficulties in very preterm children: A different etiology than Developmental Dyscalculia, Pediatric Research, 77 (2), 389-395.

Tammet, D. (2012). Thinking in numbers: On life, love, meaning and math. London: Hodder \& Stoughton. Wei, S.X. (2013). Poiesis and enchantment in topological matter. Cambridge, MA:MIT Press. 